Gut, 1961, 2, 373

\title{
An evaluation of unabsorbable markers in the study of fat absorption
}

\author{
H. S. WIGGINS ${ }^{1}$ AND A. M. DAWSON \\ From the Departments of Medicine and of Chemistry and Biochemistry, \\ the Royal Free Hospital School of Medicine, London
}

SYNOPSIS The validity of using water-soluble unabsorbable markers in the study of fat absorption was investigated.

Nine subjects were fed a finely emulsified test meal containing carbohydrate, protein, fat, and the water-soluble unabsorbable markers, polyethylene glycol, and/or phenol red. The ratio of fat to marker in recovered gastric contents was significantly different from that in the test meal. This was due to the dissociation of the meal into two phases, a solid phase rich in fat and poor in marker and a liquid phase poor in fat and rich in marker. The liquid was preferentially emptied from the stomach and also more readily sampled by a small bore tube.

When this artifact is disregarded samples obtained from the proximal small intestine would erroneously indicate an extensive and rapid absorption of fat in the duodenum and proximal jejunum.

The use of polyethylene glycol 4,000 as a nonabsorbable marker in the study of the absorption of fat, carbohydrate, and protein from the small intestine of man was introduced by Borgström, Dahlquist, Lundh, and Sjövall (1957) and is being increasingly used (Lundh, 1958: Borgström, 1960; Borgström, Lindquist, and Lundh, 1961).

When investigating fat absorption with this technique a homogeneous liquid test meal is fed and samples are recovered from the intestine through a fine plastic tube during the course of digestion. The test meal contains fat and the unabsorbable marker in a known ratio. If the ratio of fat to marker in the recovered sample is less than that in the test meal fed, this is attributed to the absorption of fat from the intestine above the point of sampling and the percentage absorption may be calculated. The assumption is made that there is no dissociation between marker and fat except that caused by the absorption of fat.

Polyethylene glycol is in many ways an ideal substance to use as a non-absorbable marker (Borgström et al., 1957). However, Lundh (1958) found the standard error of 235 duplicate determinations in intestinal contents to be $6.8 \%$. In searching for a marker substance that could be more precisely estimated, phenol red, which has been used for this

In receipt of a personal grant from the Medical Research Council. purpose in animal experiments, (Reynell and Spray, 1956) was investigated. Preliminary experiments showed that while between $70 \%$ and $80 \%$ of an intramuscular dose was excreted in the urine, less than $5 \%$ of an oral dose was recovered from the urine.

Before embarking on a large-scale study of fat absorption, using phenol red as a non-absorbable marker, the validity of the assumption of nondissociation was tested by examining the ratio of fat to phenol red in the gastric contents during digestion of a test meal. This ratio should remain the same as in the test meal, since the stomach is not known to secrete or absorb fat.

A large discrepancy was found between the ratio in the stomach contents and in the test meal. The investigation was therefore extended to include polyethylene glycol as a marker and a test meal similar to the one that Borgström had used with apparent success.

METHODS

Subjects, who were medical staff or ward patients, were fasted overnight and a gastric tube passed into the body of the stomach. The position of the tube was checked fluoroscopically and the tube fastened to the face with adhesive tape to prevent entry into the duodenum. In four of the first five subjects the position of the tube was 
checked at the end of the procedure. Four hundred $\mathrm{ml}$. of one of the test meals (see below) was fed and samples were aspirated by syringe at the times stated. The total sample recovered was analysed in studies 1-5.

In subjects 6 and 7 attempts were made to empty the stomach two hours after the meal. This was successful in subject 7 as shown by clear samples in the water washings but impossible in subject 6 owing to blocking of the tube. In studies 8 and 9, two hours after the meal the throat was anaesthetized with an anaesthetic lozenge and complete emptying of the stomach attempted by a large bore tube. Subject 8 vomited the gastric contents, but all the contents of the stomach of subject 9 were aspirated.

The composition of the two test meals used was as follows:-

Test Meal A Olive oil ...............55 g.

Gelatin ..............5 50.

Glucose...............50 g.

Phenol red ..............250 $\mathrm{mg}$.

Water .............

Test Meal B Corn oil ................. $74 \mathrm{~g}$.

Casilan ...................

Lactose . . . . . . . . . .

Glucose ...............144 g.

Polyethylene glycol .........5 g.

Phenol red .............250 mg.

Water ...............

The test meals were homogenized using a high-pressure homogenizer.

Each sample was subjected to a two-stage extraction procedure in the system water, methanol, ether, heptane, $1: 1: 1: 1$. Three lower phases were passed through two upper phases. The separating funnels were centrifuged to ensure separation of phases. The upper phases were combined and the solvents evaporated. The residual fat was weighed. The three lower phases were combined and made up to volume. Phenol red was estimated in aliquots of this solution after centrifugation to remove solids. The optical density at $580 \mathrm{~m} \mu$ was measured in a medium of $50 \%$ methanol saturated with potassium sulphate and made alkaline with potassium hydroxide under standard conditions. Polyethylene glycol was measured in aliquots of the lower phase after they had been evaporated almost to dryness to remove methanol and reconstituted with water. The method described by Hydén (1956) was used with the modification that the Somogy filtrates were passed through a mixed bed ion-exchange resin before the turbidimetric analysis.

Aliquots of the test meal administered were analysed with the gastric samples from each study and the 'expected' amount of fat calculated from this analysis.

\section{RESULTS}

The results from five studies in which serial samples were withdrawn from the stomach are presented in Table I. The column headed 'expected fat' gives the amount of fat one would expect to be associated with the phenol red or polyethylene glycol found in the sample if the ratio of fat to marker in the test meal were maintained in the stomach. The columns headed 'ratio fat: marker' give the ratio of fat to marker in the sample if by choice of appropriate units the ratio in the test meal is made 1 . It was impossible to detect any polyethylene glycol in the $165 \mathrm{~min}$. sample in study 4 . In view of the limitations of the method used in the determination this can only be interpreted as indicating a very low concentration of polyethylene glycol in this sample. The phenol red concentration was also low, being only $16 \%$ of that in the $65 \mathrm{~min}$. sample from this study.

The ratio of fat to marker differs from that in the test meal by more than $10 \%$ in all the samples. The

TABLE I

RELATION OF FAT TO MARKERS IN SERIAL SAMPLES FROM THE STOMACH

\begin{tabular}{|c|c|c|c|c|c|c|c|c|c|}
\hline \multirow[t]{2}{*}{ Subject } & \multirow{2}{*}{$\begin{array}{r}\text { Test } \\
\text { Meal }\end{array}$} & \multirow{2}{*}{$\begin{array}{l}\text { Tube } \\
\text { Internal } \\
\text { Diameter } \\
\text { (mm.) }\end{array}$} & \multirow{2}{*}{$\begin{array}{l}\text { Time } \\
(\min .)\end{array}$} & \multirow{2}{*}{$\begin{array}{c}\text { Sample } \\
\text { Volume } \\
(\mathrm{ml} .)\end{array}$} & \multirow{2}{*}{$\begin{array}{l}\text { Actual } \\
\text { Fat } \\
\text { (mg.) }\end{array}$} & \multicolumn{2}{|l|}{ Expected Fat } & \multicolumn{2}{|c|}{ Ratio Fat: Marker Test Meal $=$} \\
\hline & & & & & & $\begin{array}{l}\text { By Phenol Red } \\
\text { (mg.) }\end{array}$ & $\begin{array}{l}\text { By Polyethylene } \\
\text { Glycol (mg.) }\end{array}$ & Phenol Red & $\begin{array}{l}\text { Polyethylene } \\
\text { Glycol }\end{array}$ \\
\hline \multirow[t]{4}{*}{1} & $\mathbf{A}$ & 1.2 & 85 & 5 & 145 & 113 & & 1.28 & \\
\hline & & & 113 & 5 & 170 & 98 & & 1.74 & \\
\hline & & & 143 & 3 & 64 & 53 & & 1.21 & \\
\hline & & & 170 & 4 & 121 & 43 & & 2.81 & \\
\hline \multirow[t]{4}{*}{2} & $\mathbf{A}$ & 3 & 40 & 5 & 153 & 125 & & 1.22 & \\
\hline & & & 70 & 5 & 82 & 104 & & 0.79 & \\
\hline & & & 105 & 5 & 42 & 67 & & 0.63 & \\
\hline & & & 130 & 5 & 25 & 43 & & 0.58 & \\
\hline \multirow[t]{5}{*}{3} & $\mathbf{A}$ & 3 & 35 & 5 & 131 & 113 & & $1 \cdot 16$ & \\
\hline & & & 65 & 5 & 126 & 113 & & 1.11 & \\
\hline & & & 95 & 5 & 51 & 101 & & 0.51 & \\
\hline & & & 125 & 5 & 34 & 59 & & 0.58 & \\
\hline & & & 170 & 5 & 11 & 25 & & 0.44 & \\
\hline \multirow[t]{3}{*}{4} & B & 3 & 65 & 5 & 217 & 145 & 159 & 1.50 & 1.36 \\
\hline & & & 140 & 4.5 & 21 & 63 & 46 & $\mathbf{0} \cdot 33$ & 0.46 \\
\hline & & & 165 & 9.5 & 73 & 43 & 1 & 0.69 & \\
\hline \multirow[t]{3}{*}{5} & B & 3 & 60 & 5 & 21 & 53 & 85 & 0.40 & 0.25 \\
\hline & & & 120 & 5 & 14 & 53 & 102 & 0.26 & 0.14 \\
\hline & & & 180 & 5 & 62 & 81 & 91 & 0.77 & 0.67 \\
\hline
\end{tabular}

${ }^{1}$ No polyethylene glycol. 
TABLE II

RELATION OF FAT TO MARKERS IN ENTIRE STOMACH CONTENTS TWO HOURS AFTER FEEDING TEST MEAL B

\begin{tabular}{|c|c|c|c|c|c|c|c|}
\hline \multirow[t]{2}{*}{ Subject } & \multirow{2}{*}{$\begin{array}{l}\text { Tube } \\
\text { Internal } \\
\text { Diameter } \\
(\mathrm{mm} .)\end{array}$} & \multirow{2}{*}{$\begin{array}{l}\text { Sample } \\
\text { Volume } \\
(\mathrm{ml} .)\end{array}$} & \multicolumn{2}{|l|}{ Expected Fat } & \multirow{2}{*}{$\begin{array}{l}\text { Actual } \\
\text { Fat } \\
\text { (mg.) }\end{array}$} & \multicolumn{2}{|c|}{ Ratio Fat: Marker Test Meal $=$} \\
\hline & & & $\begin{array}{l}\text { By Phenol Red } \\
\text { (mg.) }\end{array}$ & $\begin{array}{l}\text { By Polyethylene } \\
\text { Glycol (mg.) }\end{array}$ & & Phenol Red & $\begin{array}{l}\text { Polyethylene } \\
\text { Glycol }\end{array}$ \\
\hline $\begin{array}{l}6 \\
7\end{array}$ & $\begin{array}{l}3 \\
3 \\
6 \text { (vomited) }\end{array}$ & $\left.\begin{array}{l}5 \\
5 \\
5 \\
5 \\
5 \\
5 \\
5\end{array}\right\}$ dupluplicate & $\begin{array}{r}94 \\
94 \\
72 \\
72 \\
127 \\
131\end{array}$ & $\begin{array}{l}78 \\
78 \\
47 \\
45 \\
46 \\
46\end{array}$ & $\begin{array}{r}64 \\
51 \\
84 \\
84 \\
235 \\
239 \\
\end{array}$ & $\begin{array}{l}0.68 \\
0.55 \\
1.19 \\
1.19 \\
1.86 \\
1.84\end{array}$ & $\begin{array}{l}0.83 \\
0.66 \\
1.75 \\
1.82 \\
5 \cdot 1 \\
5 \cdot 2\end{array}$ \\
\hline 9 & 6 & 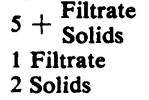 & $\begin{array}{r}99 \\
40 \\
101\end{array}$ & $\begin{array}{r}13 \\
18 \\
4\end{array}$ & $\begin{array}{r}170 \\
8 \\
238\end{array}$ & $\begin{array}{l}1 \cdot 72 \\
0.2 \\
2.36\end{array}$ & $\begin{array}{c}13 \cdot 1 \\
0.44 \\
59 \cdot 5\end{array}$ \\
\hline
\end{tabular}

range of ratios is $2 \cdot 8$ to $\mathbf{0 \cdot 1 4}$. There is no consistent pattern. In subject 1 all the ratios are greater than in the test meal while in subject 5 all are less than in the test meal.

The appearance of the samples was varied; a few, especially the earlier ones, seemed to retain the homogenity of the test meal but most contained solid and liquid phases. It was frequently difficult to obtain a sample as the tube blocked. For these reasons it was felt that the inconsistency in the results might result from the samples obtained not being representative of the total gastric contents at the time they were taken. Studies 6-9 were done to overcome the difficulty of un-representative samples by recovering the total gastric contents two hours after feeding the test meal and homogenizing externally before taking samples for analysis. The results of these four studies are shown in Table II.

Although it is difficult to be sure of the completeness of any of these collections, study 6 is the only case where the collection was obviously incomplete due to the blockage of the tube. In study 9 the gastric content was filtered through a $1 \mathrm{~mm}$. mesh wire gauze to simulate sampling through a narrow-bore tube. The solids which remained on the gauze and the fluid portion that passed through were analysed separately. The results of these analyses were combined arithmetically to calculate the composition that a $5 \mathrm{ml}$. aliquot of the total sample would have had and are presented as such as well as the analysis of the separated fractions.

Apart from study 6, where the collection was incomplete, these samples show a consistently raised fat-to-marker ratio which is especially marked for polyethylene glycol. The difference between the results obtained with the two markers probably indicated binding of the phenol red by the precipitated portion of the test meal. The separation of the solid from the liquid portion of the test meal in study 9 and the very different ratios found in the two parts lend support to the idea that the variable results in Table I are due to unrepresentative samplings.

\section{DISCUSSION}

It is obvious that the basic assumption that there is no dissociation of fat and markers in the stomach is not valid. The originally homogeneous test meal is fairly rapidly converted into a mixture of a solid phase rich in fat and poor in water-soluble marker, and a liquid phase poor in fat and rich in marker. In studies 7 to 9 the fat-to-marker ratio of the entire gastric contents recovered at two hours is higher than in the test meal. This indicates that the liquid phase leaves the stomach more rapidly than the solid, which is in agreement with the other reports on gastric digestion (James, 1957). It necessarily follows that in the portion of the test meal that has left the stomach the fat-to-marker ratio was less than in the test meal. Thus samples collected from the small intestine in this period would show apparent absorption whether in fact absorption has taken place or not.

Since studies of fat absorption from the small intestine using very similar techniques have been reported, it is important to know whether there was also a similar dissociation between fat and marker in the stomachs of the subjects used in these studies. In the absence of direct evidence of the state of the gastric contents one can only examine the reports for indications that a similar process was taking place. There are two interrelated phenomena to be taken into account: the dissociation of the test meal into solid and liquid phases with consequent dissociation of fat and marker, and the error in sampling through a small-bore tube that then arises. The first of these, coupled with the selective gastric emptying, would lead one to expect results that show a low fat-tomarker ratio in samples from the proximal small intestine during the first hours of digestion followed 
by an increase in the ratio towards the end; e.g., studies AI, AII, BI, and BII in a report by Borgström et al. (1961) show exactly this behaviour. In studies AI, AII, and BI the ratio of fat to marker of the final samples exceeded that of the test meal.

It would be expected that in spite of the selective effect of the small-bore tube for the low-ratio liquid phase occasional samples would be recovered from the small intestine with a fat:marker ratio higher than that in the test meal. The extensive discussion devoted by Lundh (1958) to this phenomenon demonstrated its occurrence in his studies also. One can only conclude that the behaviour of the test meal described in the present report was the same in the other reported studies using this technique and is probably general in this type of study. The interpretation of the results as to the site and extent of absorption of fat are of little value until it has been conclusively shown that dissociation of fat and marker, except that caused by the absorption of fat, has not taken place.

We wish to thank Mr. J. W. Hadgraft, Group Chief Pharmacist, Royal Free Hospital, for preparing the test meals.

\section{REFERENCES}

Borgström, B. (1960). Studies on intestinal cholesterol absorption in the human. J. clin. Invest., 39, 809-815.

-, Dahlquist, A., Lundh, G., and Sjövall, J. (1957). Studies of intestinal digestion and absorption in the human. Ibid, 36, 1521-1536.

_-, Lindquist, B., and Lundh, G. (1961). Digestive studies in children. Amer. J. Dis. Child., 101, 454-466.

Hydén, S. (1956). Kungl. Lantbrukshögskolans Annaler. [A turbidimetric method for the determination of higher polyethylene glycols in biological materials]. Ann. roy. Agr. Coll. Sweden, 22, 139-145.

James, A. H. (1957). The Physiology of Gastric Digestion. Arnold, London.

Lundh, G. (1958). Intestinal digestion and absorption after gastrectomy. Acta chir. scand., Suppl. 231.

Reynell, P. C. and Spray, G. H. (1956). The simultaneous measurement of absorption and transit in the gastro-intestinal tract of the rat. J. Physiol. (Lond.), 131, 452-462. 